DOI: 10.31695/IJASRE.2022.8.1.11

\title{
Smart System for Controlling and Monitoring Water and Turbidity Levels in Dam Reservoir using Micro-Controller Technology
}

\author{
Marie Chantal Iribagiza ${ }^{1}$, Kisangiri Michael ${ }^{2}$, Jema David Ndibwile ${ }^{2}$, and Felicien Sebahire ${ }^{2}$ \\ School of Computational and Communication Science and Engineering \\ Nelson Mandela African Institution of Science and Technology \\ Arusha City \\ United Republic of Tanzania
}

\begin{abstract}
A micro-controller-based technology has been developed for monitoring and controlling the water quality and quantity in dam reservoirs by using various sensors. This system is able to automatically detect and measure the changes in water and turbidity levels of incoming water for hydropower production. In this project, an Arduino UNO micro-controller and GSM Technology control the operations of the system through sending messages and regulating automatic water valves according to the instant status of the dam water. The developed prototype has four units: sensing unit, processing unit, displaying unit, and alerting unit. In the sensing unit, the ultrasonic sensor continuously monitors the change in water levels and the turbidity sensor takes turbidity measurements of incoming water. In the processing unit, the detected data are collected and fed to the microcontroller for further processing. This technology is expected to reduce the time and cost incurred during the hydropower plant operations by using a small amount of manpower and will facilitate fast information collection.
\end{abstract}

Keywords: Automation, Arduino Uno, Micro-controller, Sensors, Serial monitor.

\section{INTRODUCTION}

Dam is a man-made structure designed to hold back water for generating electricity, water supply, flood management or river flow diversion [1]. Dam and water reservoir are both built to regulate the flowing water and to store this latter for various purposes such as flood reduction, hydroelectric production, recreation, fisheries and irrigation. The most common problems encountered by the water reservoir and dams are mainly based on failure to fulfil the intended purpose which is to store water. Apart from water evaporation and water seepage, sedimentation and flooding have been reported to be serious problems for water reservoirs and dams. In hydropower production, the quantity and quality of water are monitored and controlled time to time but the use of manual and mechanical technologies result in the creation of hard-working conditions and it becomes more obvious during the rainy seasons where changes in both water quantity and quality are very important. The purpose of this research is to design a smart system for controlling and monitoring dam water reservoirs while alleviating both sedimentation and improper water allocation problems by using an Automated Microcontroller Technology.

\section{LITERATURE REVIEW}

Information of water quantity and quality is important in life-cycle of any dam reservoir in hydroelectric production. This smart system detects and takes the quick measurements of water and turbidity levels. It controls, monitors, and warns about any critical change in water level and turbidity of incoming water. This technological system reduces the time and cost incurred during the hydropower plant operations by using small amount of manpower, and facilitates fast information collection and process.

\subsection{Previous Studies}

Studies have been previously conducted at both global and regional scales and working systems have been developed to monitor and control water level and or water quality in dam reservoirs. An automated flood gate control system has been developed [2] where water level was monitored but water turbidity was not taken into consideration. Embedded water gate control systems using respectively C and Visual Basic, and Linear Predictive Coding (LPCs) were developed to control the water level where at the 
highest water level the gate is allowed to open automatically but they do not provide the time at which the gate would close if the water level is at normal condition and they didn't consider water quality [3] [4]. It is clear that water level and water quality under turbidity in our case are crucial parameters to be considered while monitoring and controlling dam water reservoirs. Currently, smart systems for controlling and monitoring water quality consist of many sensors that measure various parameters such as temperature and humidity, $\mathrm{pH}$ levels, the turbidity in the water, and water level in the storage tank [5] but no combination of these parameters has been used for reducing sediments deposition in dam water reservoir. There is a lack of using smart technology in design and operations of dam water reservoirs while alleviating both sedimentation and improper water allocation problems. And the time of information dissemination and processing is very long which consequently leads to time delays. The purpose of this research is to design a Smart System for Control and Monitoring water levels and turbidity levels in the dam reservoir of a Pico Hydropower Plant by using Microcontroller Technology. A study of a system which is Water Level Monitoring and Dam Gate Control over Internet of Things (IoT), was developed [6]. The main objective of this IoT based methodology system was to control (open and close of gate) by detecting water level in the dam. In this system, water level values were detected at different level changes. Depending on the set water level values, the dam gate might close or open, the buzzer alarmed and using the Blynk application, the people in charge were receiving through phone SMS, Email and Twitter at the same moment [6].

In 2016, T.T.Yuvarani and R.Archana developed a system that uses GSM technology for monitoring, controlling and warning of dam water level, where they used microcontroller to compare the level in the dam using the water level sensor's threshold value. The Global System for Mobile Communication (GSM) module is utilized to relay dam level status to the control room [7]. In the project research work of [8], a system for remote monitoring of a dam was developed. In India, people developed the system of dam automation using IoT, where they used python to program Raspberry pi. The gates are under automation that uses a direct current (DC) motor to control them. In this system, water level sensors are also used to collect data in order to control the gates and they use turbidity sensors to measure the turbidity of water. It also displays the status of the dam and checks the cracks of walls, so the main purposes of the system were automatic dam gate control and corrosion detection [9].

In Indonesia, researchers developed an embedded system based for power plant monitoring and controlling. This system had the importance of monitoring the environmental conditions by using various sensors, PIC microcontroller was used to read data from the different sensors, GSM was used to send the status of the boiler to the user whether for instance the temperature inside the boiler increases to the threshold value. All values were displayed on the Liquid Crystal Display (LCD) display. In this system, they considered many parameters like water, temperature, gas, and pressure levels. The main purpose of this system was to monitor and control these parameters for power plants in order to prevent the power plant wastage which affects the persons who surround the power plant [10]. In the research of dam automation and application using IoT in India, the main aim was to measure three levels of water in dam where the sensor was used to sensor the water level and when it reaches the full level reservoir the dam gate opens automatically. A relay module was used to control the opening and closing of the gate by detecting water level in the dam. The only one parameter considered was a water level [11]. An embedded system with microcontroller based can control dam system and this has been done by developing a system for detecting the level of water and the inflow water change that provide the moment of gates to be controlled in real-time by using stepper motor [12].

\section{MATERIALS AND METHODS}

In this project, the agile development methodology is used for a continuous iteration of development and testing of the viable prototype. An improvement is done for each complete stage of the system if it is found to be necessary. In our proposed system, both water level and turbidity level are monitored and when they reach to maximum levels, there is an automatic action to open or close the valve on the dam and the message is sent to the person in-charge by using GSM Module at the same time the buzzer alarms. The purpose of this project is to help the users to have the ability of remotely controlling and monitoring their dams without human interaction with the dam units. This system provides an easy way to check the information of valve function; in closing and opening. The user can control the dam from far or around and the buzzer provides an alarm when the water level goes high up. From the proposed system, the ultrasonic sensor and turbidity sensor detect water level and turbidity level respectively in the dam and then the sensed data is displayed through LCD.

\subsection{Block Diagram and System Architecture}

The proposed system has four units including sensing unit, processing unit, displaying unit and alerting unit. In the sensing unit, the ultrasonic sensor continuously monitors the change in water levels and the turbidity sensor takes turbidity measurements of incoming water (Figure 1 (b)). In the processing unit, the detected data are collected and fed to the microcontroller for further processing. The processed data is viewed on a display unit which is LCD, and the alerting unit consists of the alarm to be generated and an SMS notification to be sent (Figure 1 (a)). 


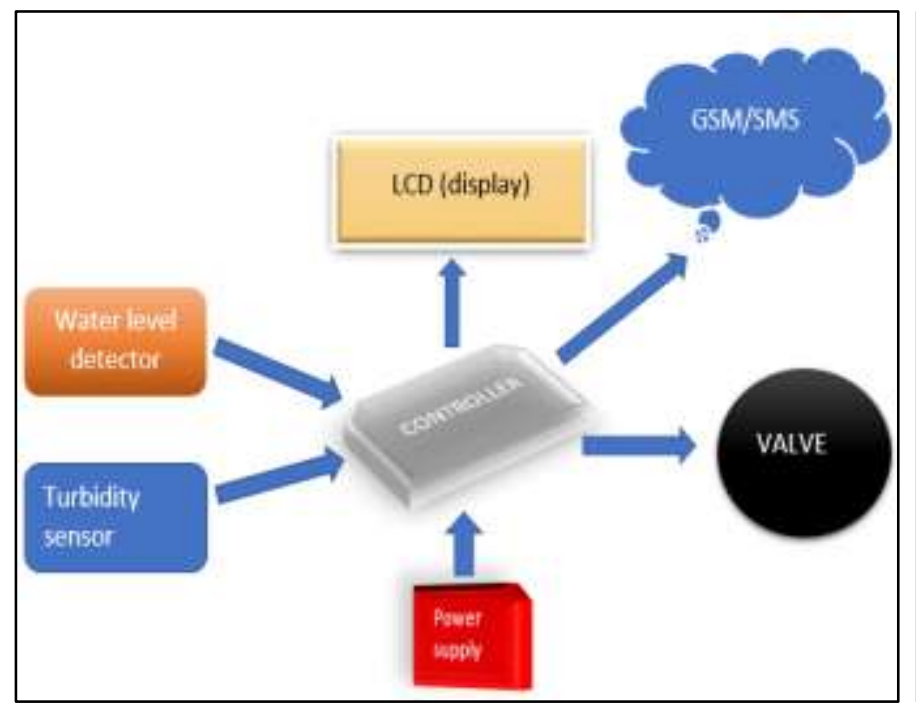

Figure 1.a. Block Diagram

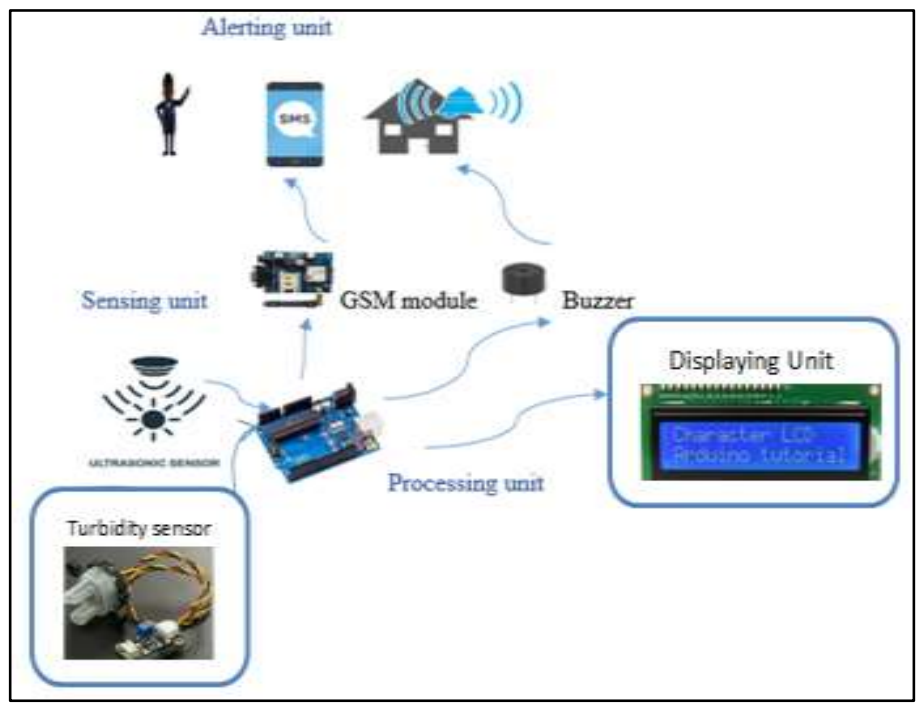

Figure 1.b. System Architecture

\subsection{Flowchart}

In the flowchart Figure 2, there is a pictorial diagram representation of an algorithm used to represent information processes for both system activity and connectivity. The activities and the connection order are shown by boxes of different kind and rows respectively. The flowchart diagram on figure below shows a by-step system operation from the start to the end.

The system was turned on and continued to run many iterations for all system components in operation and starting the initialization of set parameters. In this project study, the ultrasonic sensor and turbidity sensor were used to detect respectively water level and turbidity level in the dam water reservoir. These sensors continuously monitored the changes in water level and turbidity level and the data obtained from the sensors were sent to the micro-controller for processing and analysing. Afterward, each analysed data was compared to the required optimum. If water and turbidity levels exceed their respective thresholds, the abnormal conditions were detected, and a buzzer connected to the microcontroller was used to output an alarm for warning and notifying through Short Message Service (SMS) using the GSM module the responsible personnel to act accordingly. 


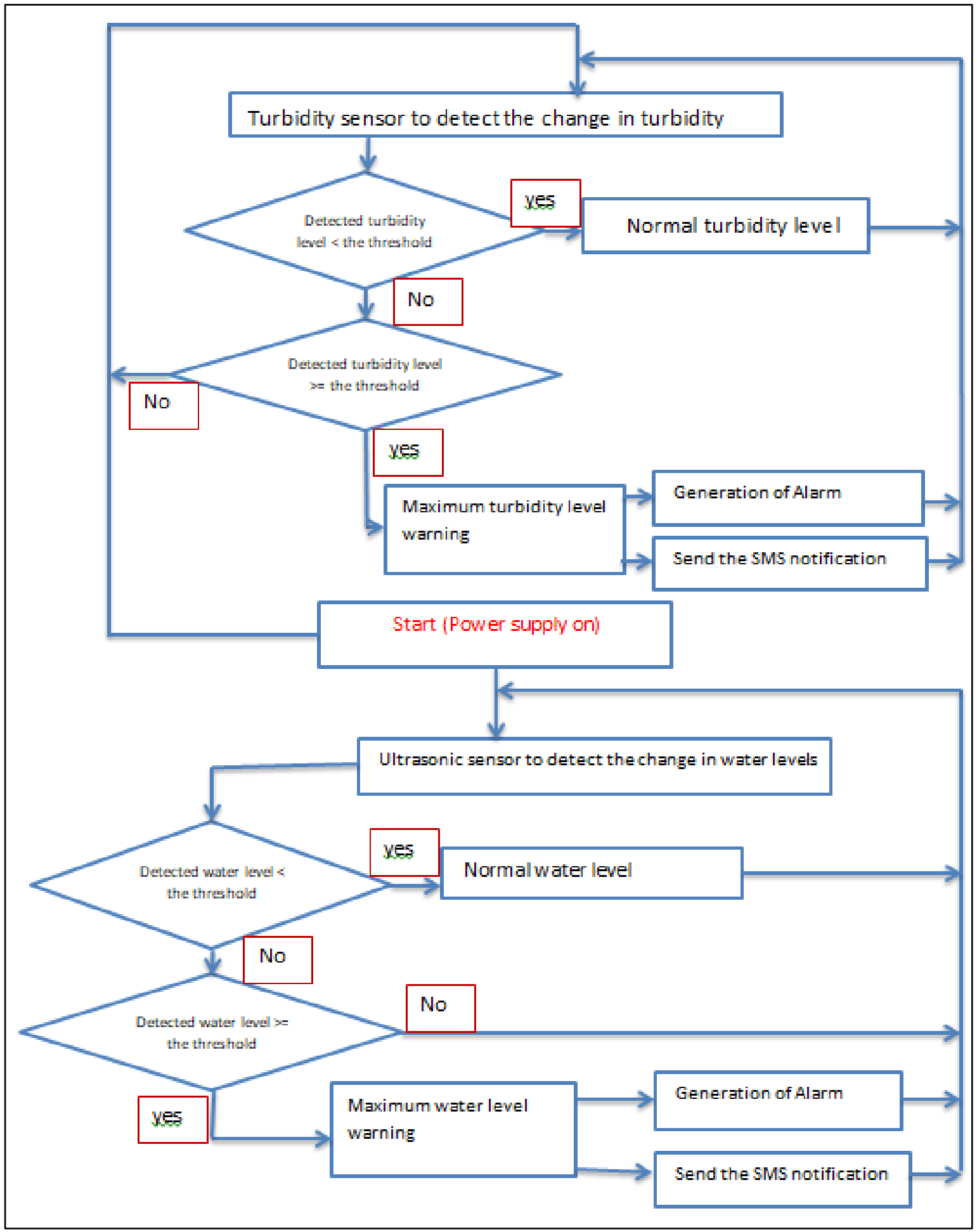

Figure 2: Flowchart of the system development

\subsection{Circuit Diagram}

The system circuit diagram graphically represents how the system components are electrically connected on Arduino Nano board (microcontroller board) in order to operate and it is represented in Figure 3. Arduino Nano has one board microcontroller that collects input information from various sensors and devices, and transforms this information into useful outputs. This Arduino Nano consists of 22 input and output pin; 14 pins are digital pins, and 8 pins are analogue pins, the turbidity sensor data pin was attached to an analog Arduino pin, which is A0. The ultrasonic sensor trig and echo pins are both connected to Arduino pins that means trig pin connected to 5 pin and echo pin connected to 6 pins. The trig pin is designed for output and the echo pin is designed for input. The pins of LCD RS, EN, D4, D5, D6 and D7 are connected to digital pins of Arduino 3, 4, 9, 10, 11 and 12. The pins of the GSM module which are transmitter and receiver are connected to 7 and 8 pins of Arduino. A wire of valve is connected to Arduino on pin 2 and a wire of buzzer is connected to Arduino on pin 13. Arduino was supplied by energy of $5 \mathrm{~V}$ to 
all these components. During the system integration process, all units were linked together. Their interaction proved the effective system functionality and its compliance with the requirements.

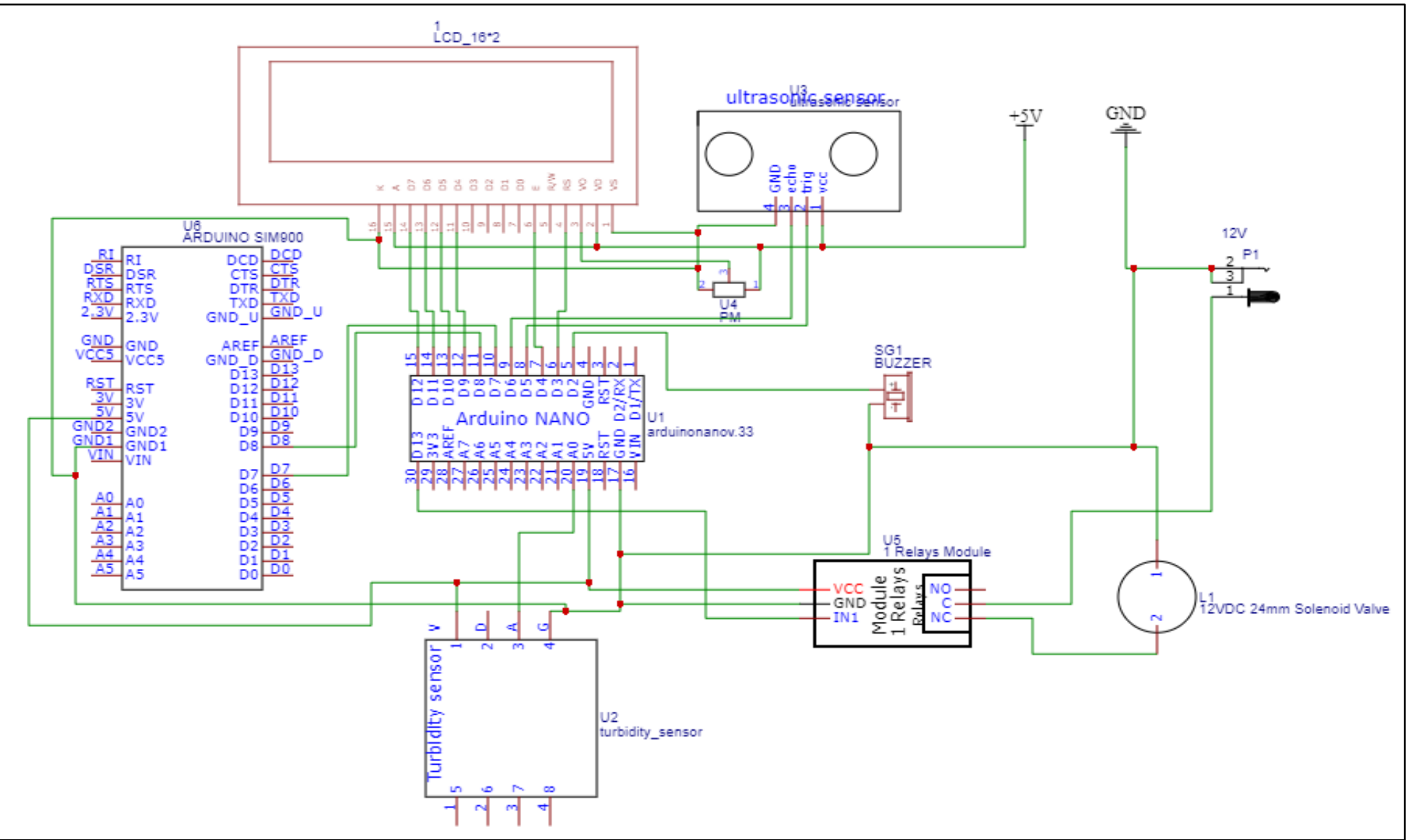

Figure 3: system circuit diagram

\subsection{Programming Languages and Software Used}

This system was built using C programming under the Arduino IDE (Integrated Development Environment). C programming is a high-level programming language and general-purpose procedure which plays important role for developing software to this language is popular programming language and it minimizes the time of execution comparatively to other high-level languages the reason why many systems and other many languages are built under C language [13]. Arduino IDE is an open-source Arduino software which is transcribed in functions after $\mathrm{C}++$ and $\mathrm{C}$ programming languages. This tool provides the ability to write and to upload the code to the Arduino board. By using this Arduino IDE, the user imports various libraries depending on the sensors or component required by the system then the output is displayed on the serial monitor window in Arduino IDE. Like other microcontrollers, ATMEGA 238 microcontroller was housed in an Arduino board and was programmed under C computer programming language. In this study, the EasyEAD software was also used. EastEDA is an online circuit drawing application which is very easy to start and understand drawing software that consists of many complex software libraries and links. Its function is simple and is easy to use. It is the type of Printed Circuit Board (PCB) design schematics and simulation for electronic circuit diagrams, the reason why it was used in this project. 


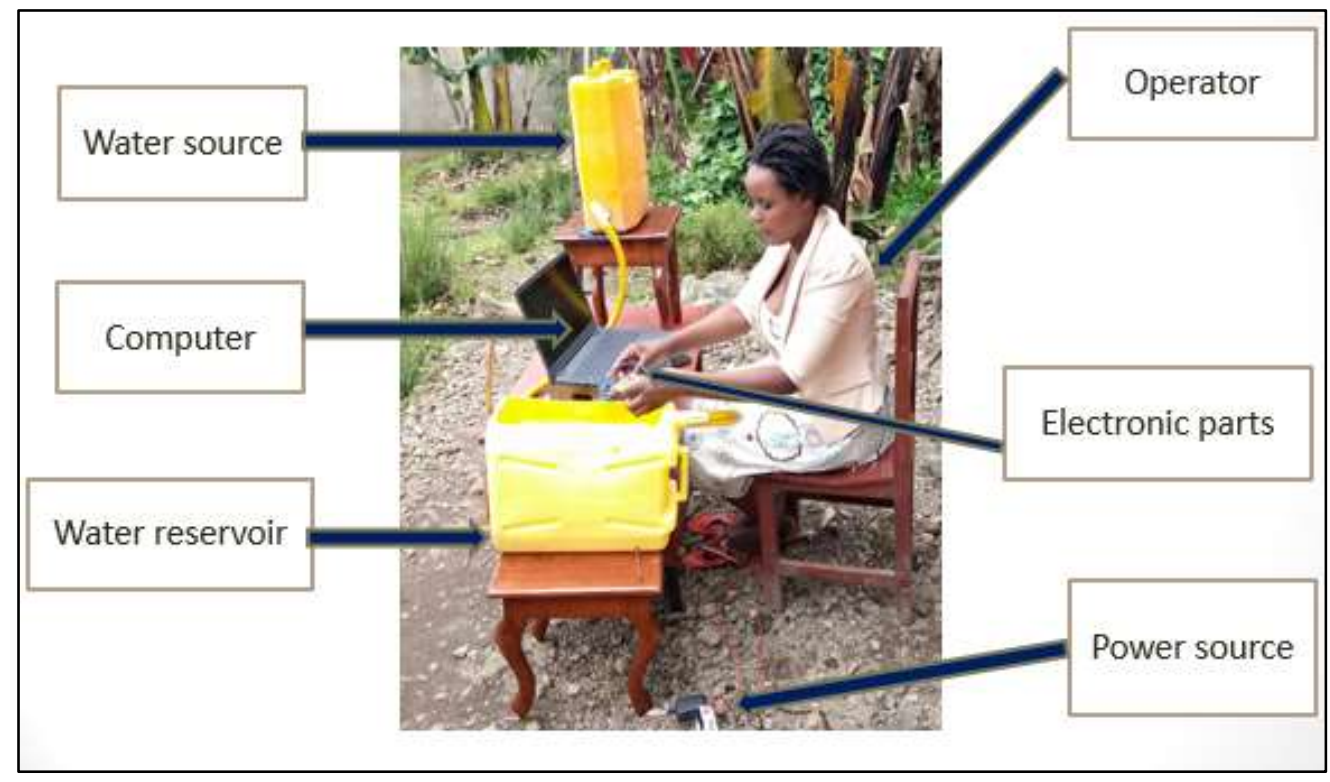

Figure 4: Prototype development

\section{RESULTS AND DISCUSSION}

\subsection{Results}

During the development and lab testing of our prototype, the measurements of the water and turbidity levels were obtained by using various hardware and software components. Two containers have been used from which the first container was considered as a source of water and the second container is a dam water reservoir. This means that the water flows from the first container to the second container through pipes with valves. The ultrasonic sensor is popular for measuring the distance in mm between sensing unit and the physical object and in this project, it starts to monitor water level in the water reservoir. Therefore, the water from the source flows into the dam water reservoir and water level in the dam is monitored. If the measured distance between ultrasonic sensor and water surface is equal to $310 \mathrm{~mm}$ which is maximum level, the dam reservoir is full, and the valve is switched off. At this time there is no water flow from the water source to the dam and the SMS notification is immediately sent to the mobile phone of the person in charge at the same time the buzzer produces an alarming sound. The SMS notification, the sound of buzzer and the low of valve are activated at the time when water level reaches its maximum level in the dam water reservoir. When the water level rises to normal state in dam, there is not alarm, no SMS notification and the valve is on until the water level reach to maximum level which is $310 \mathrm{~mm}$ and when the water level decreases to its minimum level of $330 \mathrm{~mm}$ in dam, the valve is switch on directly in order to allow water to flow from the water source to the dam water reservoir. Generally, the water level is increased when the distance between sensor and water surface is decreased. On the side of measuring turbidity level in dam water reservoirs, a turbidity sensor was used to measure the turbidity values of water in Nephelometric Turbidity Units (NTU). Turbidity is the level of cloudiness in a liquid and drinkable water has a turbidity level which is less than 4 NTU. The turbidity sensor detects and measures the variation of turbidity levels of incoming water in the dam. The normal turbidity level in water was set to be less than $50 \mathrm{NTU}$ in this project. And if it is over than this value (50 NTU), in this case the maximum turbidity level is exceeded, and the buzzer warns by producing the alarms and SMS notification is sent to the mobile phone of the person in charge. Both the turbidity level and the distance detected by the respective sensors changed more time on the LCD screen and serial monitor at the same time. The tables below display the different measurements of water level and turbidity level in dam water reservoir and their status description of dam. 
International Journal of Advances in Scientific Research and Engineering (ijasre), Vol 8 (1), January -2022

Table 1: Comparison of output measurements of water level obtained in lab testing

\begin{tabular}{|l|l|l|l|}
\hline No & $\begin{array}{c}\text { Water } \\
\text { level }\end{array}$ & \multicolumn{1}{|c|}{ Measurement of water level } & \multicolumn{1}{|c|}{ Status in dam reservoir } \\
\hline 1 & Maximum & $\begin{array}{l}\text { The measured distance between sensor and water } \\
\text { surface in dam is less or equal to } 310 \mathrm{~mm}\end{array}$ & $\begin{array}{l}\text { Bad condition, dam is full: water level in dam is at its } \\
\text { highest, but water is still controlled and no incoming } \\
\text { water. }\end{array}$ \\
\hline 2 & Normal & $\begin{array}{l}\text { The distance measured between sensor and water } \\
\text { surface is any value between } 330 \mathrm{~mm} \text { and } 310 \\
\text { mm }\end{array}$ & $\begin{array}{l}\text { Normal condition: Water level is controlled, and valve } \\
\text { is switched on and the water can enter in the dam } \\
\text { reservoir. }\end{array}$ \\
\hline 3 & Minimum & $\begin{array}{l}\text { The distance measured between sensor and water } \\
\text { surface greater or equal to } 330 \mathrm{~mm}\end{array}$ & $\begin{array}{l}\text { Bad condition: water level was low in dam, valve was } \\
\text { ON }\end{array}$ \\
\hline
\end{tabular}

Table 2: Comparison of output measurement of turbidity level in the dam water reservoir

\begin{tabular}{|l|l|l|}
\hline No & Turbidity level measurements in water dam & Status description in water dam \\
\hline 1 & The turbidity level measured $</=4 \mathrm{NTU}$ & Good condition: this turbidity is low and safe for drinking \\
\hline 2 & The turbidity level measured $>/=50 \mathrm{NTU}$ & $\begin{array}{l}\text { Bad condition: Turbidity level increases up to maximum level and } \\
\text { beyond that, it can create sediments. }\end{array}$ \\
\hline 3 & The turbidity level measured <50NTU & $\begin{array}{l}\text { Good and safe condition: Turbidity level is increasing to a high level } \\
\text { but not cause any problem in the water dam. }\end{array}$ \\
\hline
\end{tabular}

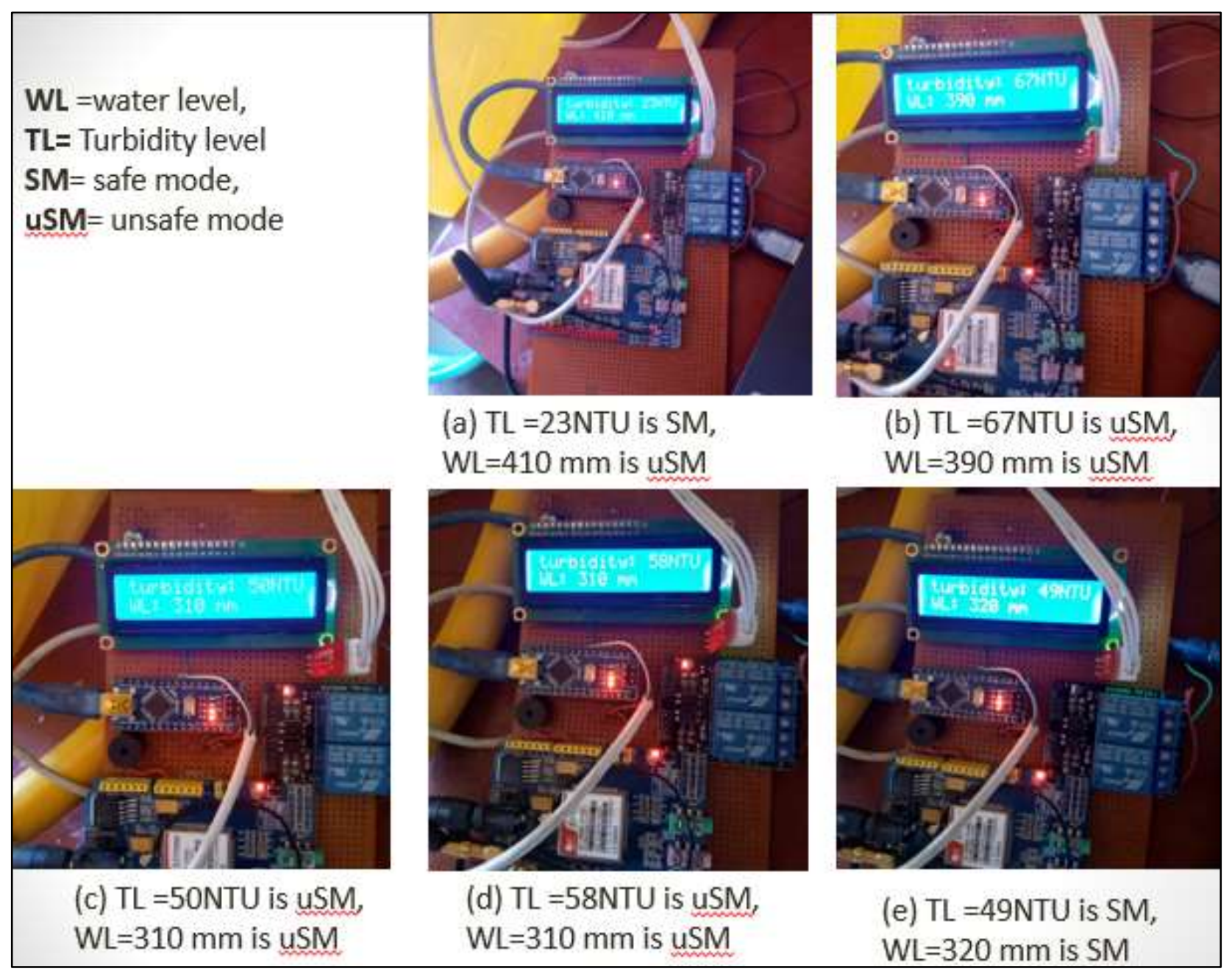

Figure 5: Results from lab system testing 


\subsection{Discussion}

The lab experiments conducted showed that both water level and turbidity levels can be automatically detected, measured and the information can be immediately shared to the dam operators. In Figure 5 and 6, the shown values were the instant water and turbidity levels from the lab experimentation. The water level distance and turbidity parameters were monitored by ultrasonic and turbidity sensors respectively. Updates of data from the sensors were provided by a serial monitor on the computer screen. The changes in both water and turbidity levels which exceed the optimum creates the generation of an alerting SMS and sound through the mobile phone and the buzzer respectively. Figure 6 shows the short messages that were sent to the phones of the dam operators to let them know that a danger state was attained. Figure 4 shows the developed lab prototype as installed. Based on the gained information about the design and implementation of a lab scale system, an automated field system can be implemented at affordable cost, accuracy, efficiency and effectiveness are assurances.
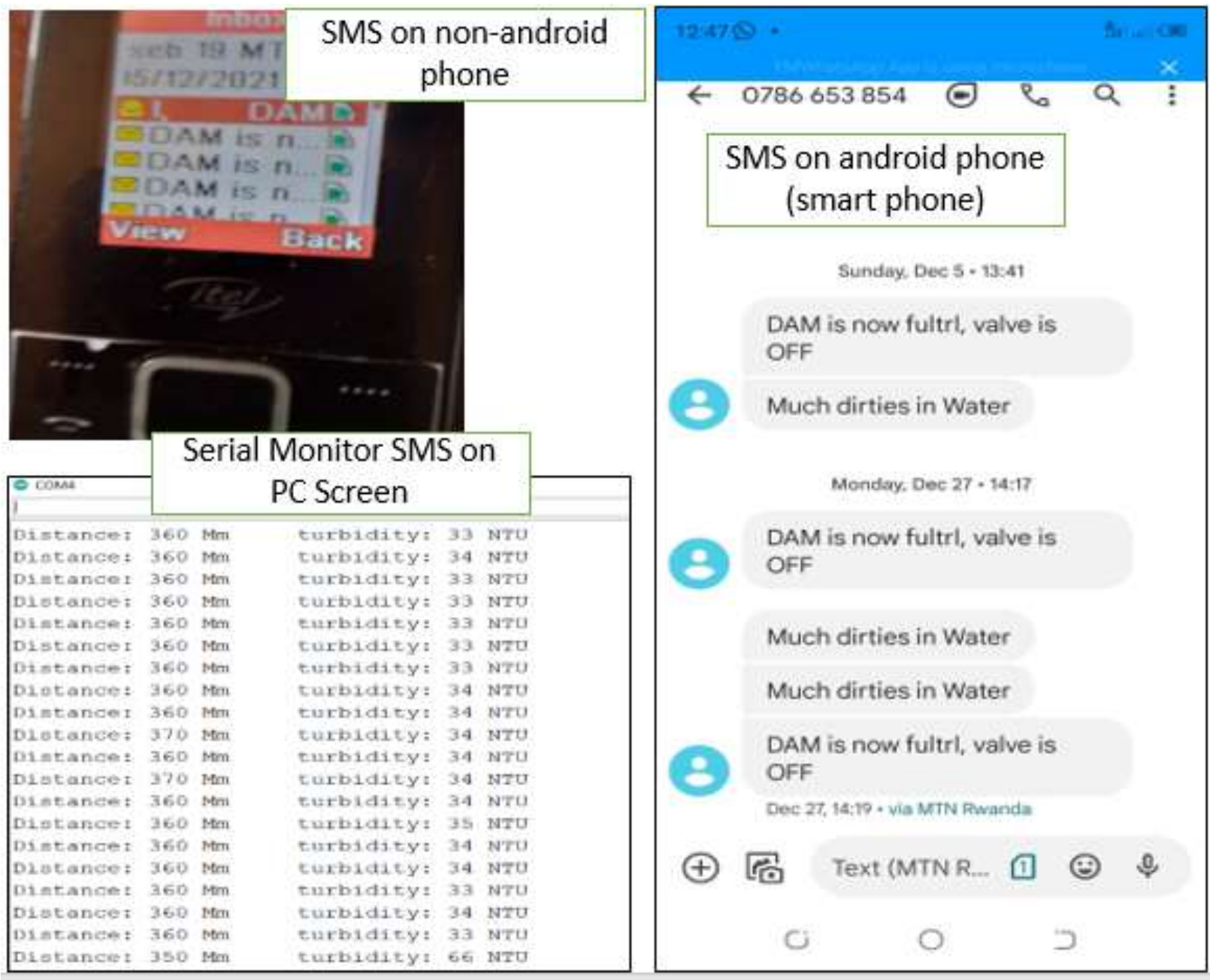

Figure 6: SMS notification to both computer and mobile phones

\section{CONCLUSION AND RECOMMENDATION}

\subsection{Conclusion}

Water level variations and changes of turbidity in any water reservoir should be controlled. If the quantity of water becomes too small, the hydropower production is negatively affected and if it turns too high, it causes inundation which creates a loss of properties and human deaths. When turbidity increases to a high level, it creates a sedimentation phenomenon which is the accumulation of sediments in the bottom of the water reservoir. Sediments tend to reduce the capacity of a water reservoir as the usable volume of water is occupied by this settled matter thus affecting hydropower production. The developed prototype system has proved that the information on water level and turbidity status can be disseminated within 3 seconds thus allowing the authorities to act accordingly. Through its functionality, this system proved to be user friendly, economically applicable and does not require rigorous maintenance. The results of this conducted study, from lab testing, have provided a smart prototype which can quickly detect the changes in both water and turbidity levels, and continuously send updates to the dam operators. 


\subsection{Recommendation and future work}

The application of smart technologies in various fields has proven to be effective and efficient. The use of Arduino microcontroller centred system would effectively improve the current systems, which are mainly manual, in control and monitoring water and turbidity levels in dam water reservoirs. The academic and research institutions, funding organizations and governments should be involved in upgrading the developed prototype, evaluating its operation for successful field implementation at large scale.

\section{Acknowledgment}

Special gratitude goes to the Centre of Excellence for ICT in EA (CENIT@EA) for being my financial support during my studies at Nelson Mandela African Institution of Science. I am extremely thankful to my host company HOBUKA Ltd staff for their contributions, especially my industrial supervisor and the company director for their time in guiding me, advice, encouragement, and their motivation which provided me to accomplish this research study.

\section{REFERENCES}

[1] Edwin Cey, J. H. (2018). Energy Education: Hydroelectric dam. Retrieved from energyeducation.ca: https://energyeducation.ca/encyclopedia/Hydroelectric_dam

[2] M. Edwin Lawrance, C. Gobiya, V. Gowsalya, R. Masi , R. M. Priyanka, 2019, Autonomous Flood Gate Control using Arduino UNO with GSM Technology, INTERNATIONAL JOURNAL OF ENGINEERING RESEARCH \& TECHNOLOGY (IJERT) ICONEEEA - 2k19 (Volume 7 - Issue 02 ), SSM Institute of Engineering and Technology, Dindigul, India.

[3] Iyer, M., Pai, S., Badri, S., \& Kharche, S. (2013). Embedded Dam Gate Control System using 'C\&apos; and Visual Basic. International Journal of Computer Applications, 69(2), 32-37. https://doi.org/10.5120/11816-7491

[4] B, O. (2018). PLC-Based Dam Automation System. (IJSRD - International Journal for Scientific Research \& Development| Vol. 6, Issue 02, 2018 | ISSN (Online): 2321-0613, n.d.)

[5] Pasika, S., \& Gandla, S. T. (2020). Smart water quality monitoring system with cost-effective using IoT. Heliyon, 6(7), e04096. https://doi.org/10.1016/j.heliyon.2020.e04096

[6] P. P. Kulkarni. (2018). Water Level Monitoring and Dam Gate Control over IOT. International Journal on Future Revolution in Computer Science \& Communication Engineering. Volume 4, Issue 4, 141-145. http://www.ijfrcsce.org/index.php/ijfrcsce/article/view/1485/1485

[7] Yuvarani, T. S., \& Archana, R. (2016). Water Level Monitor, Control and Alerting System Using GSM in Dams and Irrigation System based on Season. international Journal of Scientific \& Engineering Research. 7(4), 3.

[8] Abdullah Al-hadhrami, Z. M., \& Shaikh, A. K. (2017). A System for Remote Monitoring and Controlling of Dams. International Journal of Programming Languages and Applications, 7(4), 1-18. https://doi.org/10.5121/ijpla.2017.7401

[9] Dr. Nagesha Shivappa, Aishwarya S Rao, Aishwarya T, Jahnavi S Athreya, Mandakini H, \& JSS academy of technical education. (2020). Dam Automation using IoT. International Journal of Engineering Research And, V9(05), IJERTV9IS050617. https://doi.org/10.17577/IJERTV9IS050617

[10] Ashwin, J. S., \& Manoharan, N. (2018). Embedded System Based Power Plant Monitoring and Controlling. Indonesian Journal of Electrical Engineering and Computer Science, 9(2), 275. https://doi.org/10.11591/ijeecs.v9.i2.pp275-278

[11] RaviKumar, L., Rajeevan, J., Baiju, K., Varghese, M., Agnes, N., \& Babu, S. G. (2020). Dam Automation and Application Using IOT-(A Prototype Model Study). 66(90), 5.

[12] Vinayak .S.W: K.M.Kavitha; B. Kantharaj: Vinaya Kumara M. B. (2016). MICROCONTROLLER BASED DAM GATE control system. International Journal of Scientific Development and Research (IJSDR), Volume 1, Issue 5 (629-634)

[13] Agnihotri, N. (2021, October 20). Arduino compatible coding 03: Basics of Arduino sketches and Embedded C. Retrieved from Engineers Garage: https://www.engineersgarage.com/articles-basics-of-arduino-sketches-arduino-c/ 


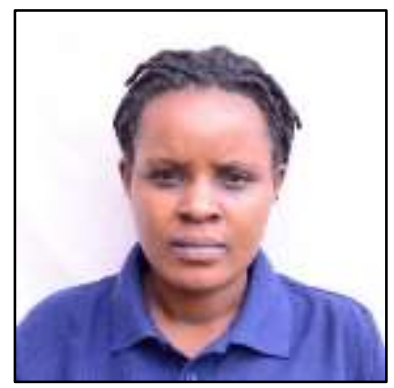

Marie Chantal Iribagiza born in Musanze District, North Province of Rwanda. She is a Master's candidate in Embedded and Mobile System in specialization of Embedded System at Nelson Mandela African Institution of Sciences and Technology (NM-AIST). She has an academic background in computer science and systems with a bachelor of science from University of Rwanda. She is an instructor of IT at Muhabura Integrated Polytechnic College (MIPC) and her interests lie in developing ICT tools for education and business oriented projects. Email: iribagizam@nm-aist.ac.tz

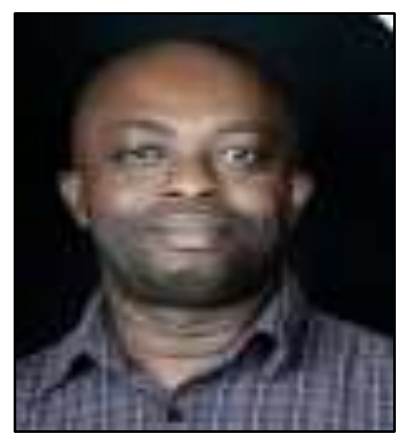

Dr. Kisangiri Michael has been working with NM-AIST as lecturer then Senior lecturer since December 2011. Before joining NM-AIST, he worked with Dar-es Salaam Institute of Technology in the position of lecturer for 3 years. He is a $\mathrm{PhD}$ holder in the field of Telecommunications, with which he graduated from Wroclaw University of Technology - Poland. currently he is working as academician and has supervised dozens of MSc and several $\mathrm{PhD}$ researches. He possesses good knowledge in Artificial intelligence, Antenna design, and wireless communication systems. He is fluent speaker of three languages: Swahili, English, Polish. Email: kisangiri.michael@nmaist.ac.tz

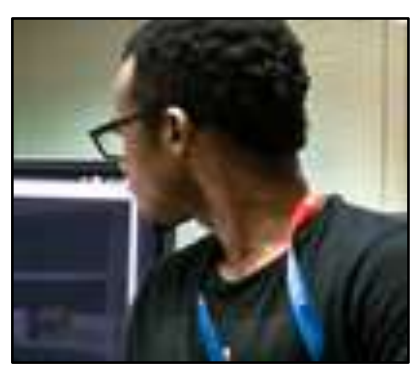

Dr. Jema D. Ndibwile is a Computer Scientist and a Lecturer at NM-AIST and the Tanzania Communication Regulatory Authority (TCRA) representative on cybersecurity issues at NMAIST. Prior to that he was a senior IT System administrator and one the pioneers of the NM-AIST computer systems and networks. He has a doctorate degree in Information Security from Nara Institute of Science and Technology in Japan which he attained in 2019. His general research interests are in the areas of Cybersecurity, Cryptography, Ethical Hacking, The Psychology of Cybersecurity and Network Engineering to help resolve complex security challenges. Currently his research work is focused more on predicting cyberattacks through Artificial Intelligence and Human Intelligence. Email: jema.ndibwile@nm-aist.ac.tz

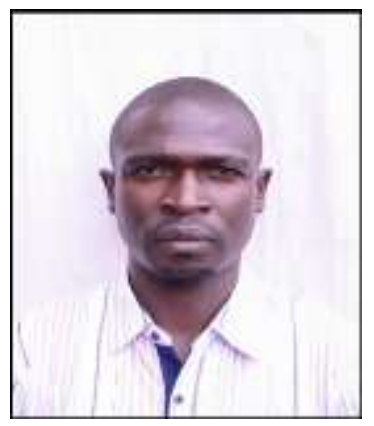

Eng. Felicien Sebahire has a background in civil engineering, hydraulic structures, water supply and sanitation. He serves as an assistant lecturer of various civil and environmental courses at Rwanda Polytechnic (RP) and currently he is a lecturer at Muhabura Integrated Polytechnic College (MIPC) and well engaged in projects design and implementation namely: construction, irrigation, water supply and waste management. He has a MSc. in water and sanitation, and a bachelor's degree in civil engineering. Email: feliba01@gmail.com 